\section{Developments and Applications in Solubility}

Solubility is a basic phenomenon underlying most industrial processes. The objective of this project is to produce a book that will bring together recent developments in solubility studies that have a bearing on industrial applications, especially the rigorous work that is underpinned by thermodynamic considerations.

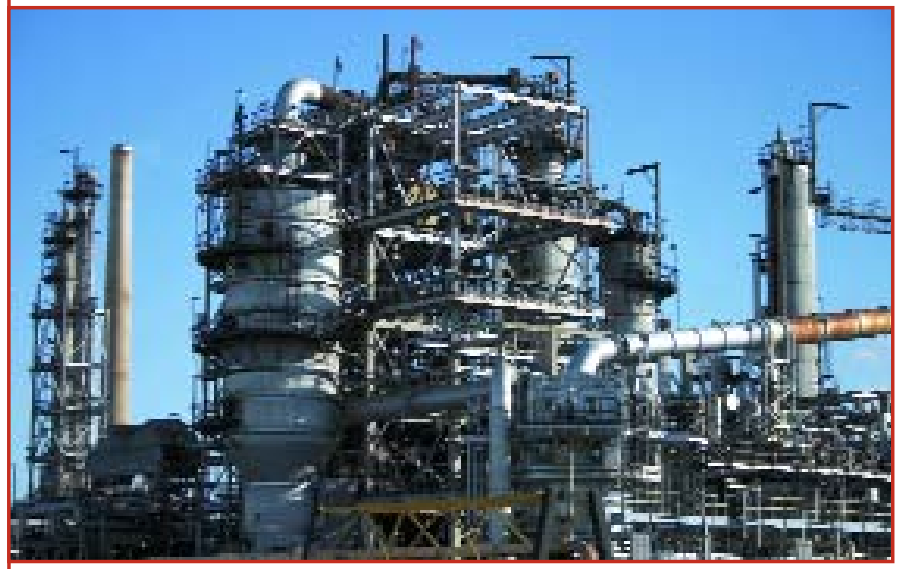

The book will highlight important areas of new research involving theory, techniques, results, modeling, simulation, and industrial applications related to solubility. It will include chapters on super-critical fluids, data banks, "green chemicals," molten salts, liquid-liquid phase equilibria, nanotechnology, industrial solutions including cryogenic solutions, predictions, simulations and molecular modeling, gases in polymers, metallurgical and hydrometallurgical processes, separation processes, and the food, pharmaceutical, and cosmetics industries.

For more information or to comment on this project, contact Task Group Chairman Trevor M. Letcher <trevor@letcher.eclipse.co.uk〉.

\section{www.iupac.org/projects/2005/2005-016-1-100.html}

Trevor M. Letcher's most recent book, Chemical Thermodynamics for Industry, was published in October 2004 by the Royal Society of Chemistry (ISBN 085404591 0). It presents the latest developments in applied thermodynamics and highlights the role of thermodynamics in the chemical industry. To learn more about the book, go to <www.iupac.org/publications/books/author/ letcher04.html.>

\section{Glossary of Terms Related to Solubility}

This project will define terms related to the phenomenon of solubility, including both experimental and theoretical aspects of gas-liquid, liquid-liquid, and solid-liquid solubility. The terms and definitions will be presented in glossary format and published as IUPAC Recommendations in Pure and Applied Chemistry. The glossary will be made available for inclusion in the IUPAC Compendium of Chemical Terminology (the Gold Book) and the Compendium of Analytical Nomenclature (the Orange Book) as well as in other non-IUPAC publications.

For more information, contact Task Group Chairman David Shaw <ffdgs@uaf.edu>.

www.iupac.org/projects/2005/2005-017-1-500.html

\section{e-Quiz for Promoting Chemical Education}

A chemistry quiz titled "Rasayanika" ("chemistry" is "rasayan" in Sanskrit) was conducted in Delhi in 2003 under the auspices of the JK Foundation for Human Development (JKFGD). JKFGD is a part of the JK Organization, one of the most prestigious industrial houses in India. The quiz was an adaptation of the pioneering Australian National Chemistry Quiz developed by Dr. Charles Fogliani under the auspices of the Royal Australian Chemical Institute. Dr. Fogliani has been conducting his quiz in the Australasian region since the 1980s.

Rasayanika was designed to improve awareness of the role that chemistry plays in everyday life in a developing country like India. The highly enthusiastic response from students and teachers in 2003 led to the idea of conducting the quiz outside Delhi in 2004.

Moving Rasayanika to an online format is now desirable; doing so will allow the quiz to reach a wider audience and will professionalize the assessment tools and techniques, allowing Rasayanika to become a catalyst for improving student interest in chemistry. To enable the participation of schools where chemistry is not taught in English, the online version will also be accessible in local languages.

The objective of this project is to design the online version of the exploratory trials conducted in 2003 and 2004. An online quiz will allow students from across India to participate in the 2005-2006 quiz and 